\title{
PEMBERDAYAAN DESA MELALUI PELATIHAN PENGOPERASIAN MICROSOFT EXCEL DALAM ADMINISTRASI DATA MATEMATIS DESA
}

\author{
Tri Andari ${ }^{1}$, Restu Lusiana ${ }^{2)}$ \\ ${ }^{1)}$ FPMIPA, IKIP PGRI Madiun \\ email: triandari229@yahoo.com \\ ${ }^{2)}$ FPMIPA, IKIP PGRI Madiun \\ email: lucie.azzura@yahoo.com
}

\begin{abstract}
The purpose of this training is that trainees are able to master the operation of Microsoft Excel for data processing mathematical administration in the village. Operation of Microsoft Excel training activities carried out in two village in the district Panekan partners namely in the village and the village Milangasri Wates. Training activities conducted using survey methods, lectures, practical training and consultation discussions. In this community service activities we undertake the operation of Microsoft Excel training for administrative data processing mathematically in the village. To know the indicators of achievement of the control operation of Microsoft Excel training participants we conducted a series of evaluations at each stage of activity. From the results of the evaluation carried out, showing that the operation of Microsoft Excel training is effective, it can be seen from the enthusiasm of the participants in the training. Given that most of the data processing mathematical administration in the village do with Microsoft Excel so by mastering how to operate the program, the data can be documented village easier, faster, and more complete. It is an indicator of the importance of improving the quality of village administration services and related processes performed by the village. The enthusiasm and activeness of the participants showed that this training is required by the Village.
\end{abstract}

Keywords: Empowerment, Training, Microsoft Excel, Data Administration Mathematical

\section{PENDAHULUAN}

\section{a. LATAR BELAKANG}

Kabupaten Magetan memiliki luas seluruh $688,85 \mathrm{Km} 2$ yang terdiri dari 19 kecamatan, 235 desa/kelurahan, $1.085 \mathrm{RW}$ dan 4.640 RT. Kecamatan Panekan adalah salah satu kecamatan yang ada di kabupaten Magetan. Di kecamatan ini terdiri dari 16 desa dan 1 kelurahan. Sistem administrasi yang dilaksanakan di kantor-kantor desa di Kecamatan tersebut selama ini sama dengan desa-desa lainnya di Kabupaten Magetan yaitu masih berupa sistem administrasi konvensional dan belum berbasis komputer. Salah satu sebabnya karena perangkat desa belum menguasai teknologi informasi dan komunikasi (Komputer). Rendahnya pengetahuan mengenai sistem administrasi berbasis komputer dan kurangnya penguasaan terhadap teknologi informasi dan komunikasi menyebabkan dokumentasi data desa tidak tertib, tidak lengkap, dan tidak akurat.

Penerapan Microsoft Office dalam segala bidang telah banyak dilakukan, salah satu diantaranya adalah untuk pengolahan data administrasi matematis di desa. Pengolahan administrasi data matematis di desa dapat dilakukan dengan menggunakan Microsoft Office Excel. Microsoft Excel adalah Program aplikasi pada Microsoft Office yang digunakan dalam pengolahan angka (Aritmatika). Data yang tersimpan serta diolah dengan baik sangat mendukung serta mempermudah kinerja pemerintah desa. Data administrasi matematis desa yang dapat diolah menggunakan Microsoft Excel diantaranya adalah untuk menghitung jumlah penduduk, membuat laporan keuangan, menghitung anggaran pengeluaran pembangunan, membuat rincian penggunaan dana bantuan, merinci rincian penggunaan dana karang taruna, merekap data mutasi penduduk dan rekapitulasi jumlah, dan lain-lain.

Kondisi masyarakat di kecamatan Panekan sebagian besar rata-rata tingkat pendidikannya menengah ke atas sehingga memiliki tuntutan akan kualitas layanan yang tinggi dalam berbagai hal. Sementara itu hampir seluruh aparat pemerintahan di kecamatan 
tersebut yang terdiri dari Kepala Desa dan Perangkat Desa lainnya adalah pejabat yang dipilih oleh penduduk secara langsung dan bukan pegawai negeri sipil. Sebanyak $82,84 \%$ di antaranya berpendidikan setingkat SLTA dan $7,46 \%$ berpendidikan setingkat Diploma/Sarjana. Lebih dari $70 \%$ diantaranya berusia antara 30 - 50 tahun. Dalam hal kemampuan menangani administrasi serta pendokumentasian data desa, rata-rata Kepala Desa, Sekretaris Desa, dan Perangkat Desa lainnya masih tergolong rendah terbukti dari hasil observasi secara acak terhadap dua desa di Kecamatan Panekan yaitu desa Wates dan desa Milangasri, di diketahui bahwa sistem administrasi desa hampir seluruhnya masih dikerjakan secara manual belum menggunakan perangkat komputer. Lebih dari $90 \%$ data desa adalah data dari dua hingga tiga tahun yang lalu dan ragam data juga tidak lengkap. Meskipun tiap-tiap pemerintahan desa telah dilengkapi dengan komputer namun perangkat tersebut belum dapat dimanfaatkan secara maksimal karena belum adanya tenaga yang memiliki kemampuan untuk mengoperasikannya. Lebih dari $90 \%$ perangkat desa belum terampil mengoperasikan perangkat komputer karena belum pernah mendapat pelatihan tentang hal tersebut.

Permasalahan tersebut sangat tidak mendukung terwujudnya citra perangkat desa sebagai seorang yang profesional, yang melayani segala kebutuhan masyarakat. Seharusnya mereka dapat menguasai pengoperasian Microsoft Excel untuk mengoptimalkan pemanfaatannya. Keterbatasan kemampuan tersebut sangat dimungkinkan dikarenakan keterbatasan pelatihan yang dapat diikuti oleh perangkat desa. Oleh karena itu perlu diselenggarakan pelatihan pengoperasian Microsoft Excel. Pelatihan komputer yang dilakukan sesuai dengan kebutuhan perangkat desa diharapkan dapat menjadi salah satu alternatif penyelesaian permasalahan tersebut.

\section{b. TUJUAN}

Melalui kegiatan pelatihan ini diharapkan dapat meningkatkan keprofesionalan perangkat desa dalam melaksanakan kegiatan yang berkaitan dengan pelayanan administrasi desa.

\section{c. TARGET DAN LUARAN}

Target dan luaran yang diharapkan dari penelitian ini adalah sebagai berikut:

1) Peserta pelatihan diharapkan dapat menguasai pengoperasian Microsoft Excel untuk pengolahan administrasi data matematis di desa.

2) Peserta pelatihan termotivasi untuk meningkatkan mutu pelayanan administrasi desa dan proses yang terkait yang dilakukan oleh perangkat desa.

\section{METODE PELAKSANAAN PROGRAM}

Kegiatan pelatihan yang diselenggarakan dilakukan dalam tiga tahapan dan setiap tahapan menggunakan metode survei, ceramah, praktek pelatihan, diskusi-konsultasi, dan evaluasi. Metode yang dilakukan adalah sebagai berikut:

a. Survei dilakukan sebelum pelaksanaan pelatihan.

b. Ceramah penjelasan diberikan kepada peserta dalam hal pengeksplorasian lebih dalam terhadap fitur-fitur perangkat lunak bantu yang dapat digunakan untuk pengolahan data administrasi matematis desa menggunakan Microsoft Excel.

c. Penjelasan disertai langsung dengan praktek pelatihan.

d. Selama pelatihan peserta difasilitasi dalam melakukan diskusi-konsultasi untuk membahas permasalahan yang timbul dalam pengolahan data administrasi matematis desa.

e. Pada akhir pelatihan, diedarkan angket evaluasi untuk mengetahui respon peserta terhadap pelatihan yang diselenggarakan dan menjaring saran-saran untuk tindak lanjut pelatihan.

\section{HASILDAN PEMBAHASAN}

Kegiatan pengabdian pada masyarakat yang berupa pemberian pelatihan Microsoft Excel dalam administrasi data matematis desa ini dilaksanakan selama 3 hari yaitu pada hari tanggal 3, 10, dan 17 Mei 2014, yang bertempat di kantor desa Milangasri yang dimulai jam 08.00 - 13.00 WIB atau selama 300 menit setiap harinya termasuk istirahat 30 menit. Kegiatan diikuti 16 orang Perangkat desa yang merupakan perwakilan dari 2 desa di wilayah kecamatan Panekan.

Berdasarkan pada hasil pretest peserta yang menunjukkan bahwa rata-rata peserta belum mampu mengoperasikan Microsoft Excel, bahkan beberapa peserta belum menguasai pengoperasian Microsoft Word, untuk itu sebelum memberikan materi tentang Microsoft Excel terlebih dahulu diberikan materi tentang pengoperasian Microsoft Word. Pelatihan dilakukan dalam tiga tahapan mengingat banyaknya materi yang diberikan dan 
setiap tahapan terdiri dari metode survei, ceramah, praktek pelatihan, diskusi-konsultasi, dan evaluasi. Pada tahapan akhir peserta diberikan kesempatan untuk berkonsultasi sebagai pemantapan akhir materi pelatihan.

Berdasarkan hasil evaluasi pelatihan diperoleh bahwa penguasaan pengoperasian Microsoft Excel dalam administrasi data matematis di desa efektif. Hal ini dapat terlihat dari antusiasme peserta dalam mengikuti pelatihan diantaranya adalah banyaknya peserta yang hadir dalam pelatihan dan banyaknya peserta yang bertanya jika menemui kesulitan dalam pengoperasian Microsoft Excel. Mengingat bahwa sebagian besar pengolahan administrasi data matematis di desa dilakukan dengan program Microsoft Excel sehingga dengan menguasai cara mengoperasikan program tersebut dimungkinkan data desa dapat didokumentasikan dengan lebih mudah, lebih cepat, dan lebih lengkap. Hal ini menjadi indikator pentingnya meningkatkan mutu pelayanan administrasi desa dan proses yang terkait yang dilakukan oleh perangkat desa. Antusiasme dan keaktifan peserta menunjukkan bahwa pelatihan ini sangat diperlukan oleh Perangkat Desa, bahkan hampir semua peserta meminta agar pelatihan dilanjutkan dan ditambah materi tentang cara mengakses Internet dan membuat Web Blog.

\section{KESIMPULAN}

Berangkat dari paparan hasil dan pembahasannya, dapat ditarik simpulan mengenai kegiatan pengabdian pada masyarakat ini sebagai berikut:

a. Para peserta yang mengikuti pelatihan dapat menguasai pengoperasian Microsoft Excel untuk pengolahan administrasi data matematis di desa.

b. Peserta pelatihan termotivasi untuk meningkatkan mutu pelayanan administrasi desa dan proses yang terkait yang dilakukan oleh perangkat desa.

\section{REFERENSI}

http://id.wikipedia.org/wiki/Kabupaten_Maget an

http://id.wikipedia.org/wiki/Microsoft_Excel. 